\title{
MEASUREMENT OF STRAINS AND PRESSURE IN A SNOW COVER ON A SLOPE
}

\author{
by
}

\author{
Hiromu Shimizu, Eizi Akitaya, Mitsuo Oh'izumi and Yauso Hirabayashi \\ Institute of Low Temperature Science, Hokkaido University, Sapporo, Japan
}

\section{ABSTRACT}

Four methods of measuring strain and pressure in a snow cover on a slope are presented. The hole-mark method and short-span deformation gauge are used to measure the internal strains of snow, the long-span deformation gauge to measure the local extension/contraction of a snow cover, and snow pressure gauge to measure the pressure in a snow cover.

\section{INTRODUCTION}

Strain and stress in snow are basic parameters for studying the behavior of a snow cover on a slope. From this standpoint, four methods of measuring deformation/pressure in snow have been developed to determine strain/stress, by our laboratory. All are based on an assumption that motion of a snow cover on a slope is 2-dimensional flow in a vertical plane along the maximum slope, if the contour lines of the slope are straight and parallel.

\section{HOLE-MARK METHOD (Shimizu)}

Internal strains of the snow cover on a slope are determined by this mechanical method (Shimizu and Huzioka 1975). The original instruments were large and heavy, requiring at least three persons for handling; the latest version is compact and light, and measurement with a higher accuracy than before can be made by one person.

By the use of a wall-smoother and a ground-line fixed on a slope parallel to the contour line (Figure 1a), vertical walls along the maximum slope could easily be cut out from the snow cover at successive positions along the ground-line. Five fine straight holes, each 6 $\mathrm{mm}$ in diameter and $40 \mathrm{~cm}$ in length, were bored as a set in parallel to the ground-line in a homogeneous layer of the snow cover, using a 5-hole boring device (Figure 1b).

The initial configuration of five holes, a square of $4 \mathrm{~cm} \times 4 \mathrm{~cm}$ and its center, was photographed with scale and a vertical pendulum. Then the wall was buried with snow. The final configuration of holes was photographed on a new wall advanced by $35 \mathrm{~cm}$ along the ground line from the initial wall, after an
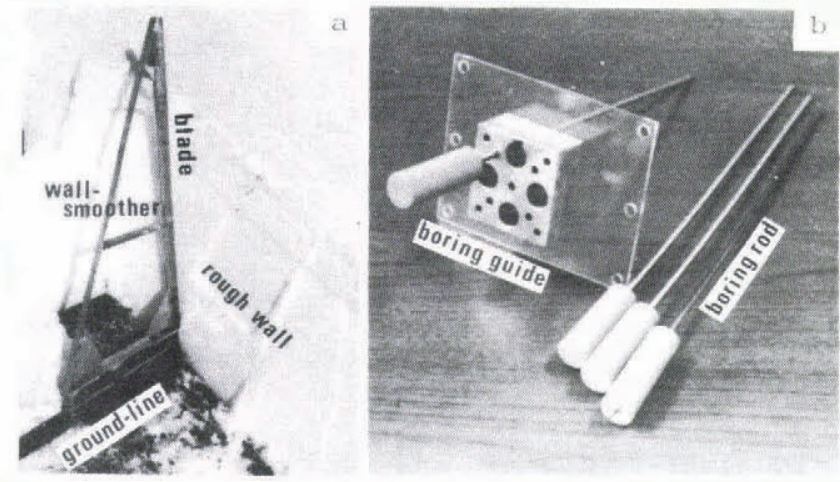

Fig.1. Instruments for Hole-mark method. a: wall-smoother, b: 5-hole boring device. appropriate time interval. A new set of holes was bored in the final wall for a successive measurement.

Although displacements of 3 points (holes) are necessary and sufficient for the calculation of homogeneous strain, the five holes were bored to check if homogeneous strain really took place or not. It was confirmed that strain of snow in a homogeneous laye could be well approximated by a finite homogeneous strain, especially for a uniform slope. Therefore, the principal axes of strain, the principal strains and their rates in a homogeneous layer were calculated.

\section{SHORT-SPAN DEFORMATION GAUGE (Hirabayashi)}

To measure the extension/contraction of snow in a small domain, preliminary measurements were made in winter 1984, using a newly designed electric deformation gauge. The gauge (Figure 2a) consists of a magnetic sensor (Hall IC) $\mathrm{H}$ fixed inside a cabinet $\mathrm{A}$, a permanent magnet (alnico) M connected with a saw-tooth plate $P_{1}$ by a rod sliding through the cabinet, and another saw-tooth plate $P_{2}$ fixed to the outside of the cabinet A. Fixing the saw-tooth plates firmly in snow,

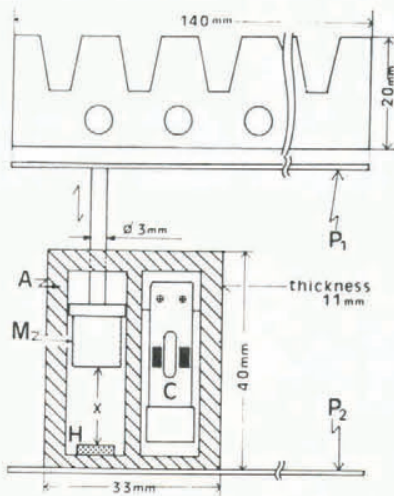

(a)

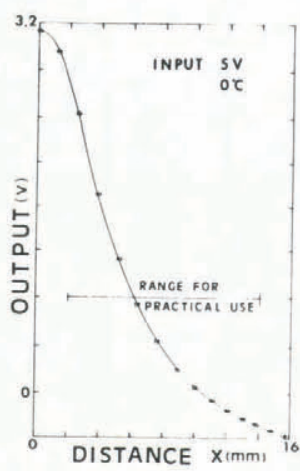

(b)
Fig.2. Short-span deformation gauge. a: the gauge; b: characteristics.

extension/contraction of snow changes the distance between the Hall IC $H$ and alnico $M$, resulting in change of the voltage output of the Hall effect sensor. As seen in Figure 2b, sensitivity of the gauge was about $4 \times 10^{-2} \mathrm{~mm}$ in the central region which corresponded to a strain of $1 \times 10^{-3}$ approximately. The inclination of the gauge was monitored by a built-in clinometer $\mathrm{C}$.

For setting the gauge, a snow block, approximately $20 \mathrm{~cm} \times 20 \mathrm{~cm} \times 60 \mathrm{~cm}$, was taken out from a pit-wall in the snow cover to build a cavity, using a sepcially designed device. Then a gauge was set on an inner wall of the cavity depending upon the direction of measurement, removing a small amount of snow for the cabinet $A$ of the gauge and thrusting the saw-tooth plates fully in the snow. Finally, the block was put back in its place, and the pit was buried with snow. The outputs of the gauge (Hall IC and clinometer) were recorded continuously. 
After the experiments, it became clear that the cabinet A should be outside of the set of saw-tooth plates not to change mechanical conditions of snow between the plates.

\section{LONG-SPAN DEFORMATION GAUGE (Akitaya)}

To measure the local extension/contraction of a snow cover on a slope, this electrical gauge was designed and used in the field in winter, 1984. The gauge (Figure 3) consists of a linear potentiometer $(2 \mathrm{k} \Omega / 20 \mathrm{~cm}) \mathrm{C}$, and a measuring rod composed of 2 sliding pipes $A$ and $B$ with hooks (aluminium angle bar) $D_{1}$ and $D_{2}$ at both ends of the rod.

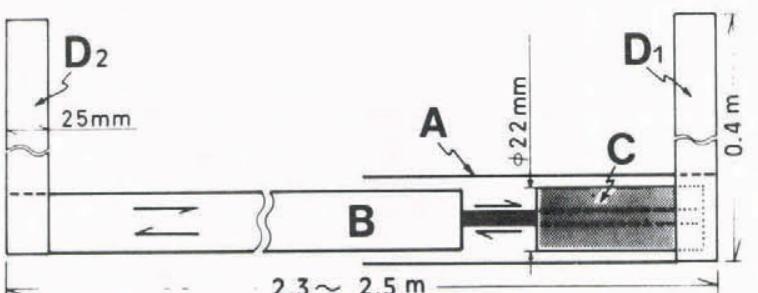

Fig.3. Long-span deformation gauge.

Cutting out a long wall of a snow cover along the maximum slope, the gauge was fixed on the wall by thrusting the hooks $D_{1}$ and $D_{2}$ in the snow until the pipe $\mathrm{A}$ touched the snow wall. Because the working distance of the potentiometer $\mathrm{C}$ was $20 \mathrm{~cm}$ in length, initial length of the measuring rod was adjusted in a range of $2.3-2.5 \mathrm{~m}$ according to the stress condition of the snow cover.

Output of the potentiometer $A$ was recorded continuously by a digital recorder. Apparent sensitivity of the measurement was $0.8 \mathrm{~mm}$ which corresponded to a strain of $3 \times 10^{-4}$ approximately, affected by the resolving power of the recorder.

\section{SNOW PRESSURE GAUGE (Oh'izumi)}

A thin-disc type of snow pressure gauge $(18 \mathrm{~cm}$ in diameter, $0.6 \mathrm{~cm}$ in thickness and $258 \mathrm{~g}$ in weight: Figure 4a) was made to determine stresses in snow

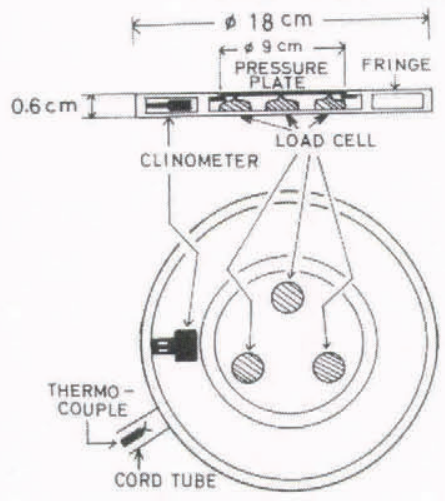

Setting device

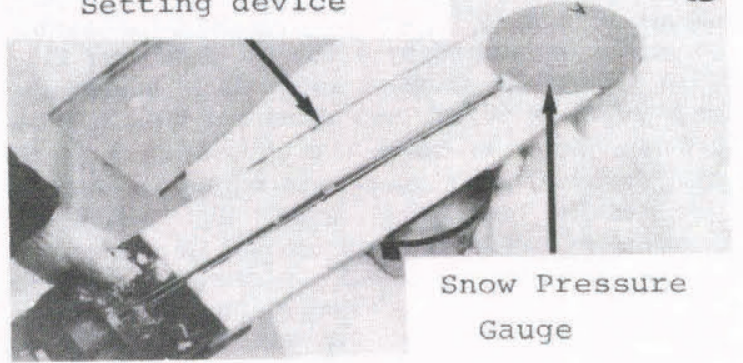

Fig.4. Snow pressure gauge. a: the gauge; b: setting device.

cover. The snow force working on the pressure plate ( 9 $\mathrm{cm}$ in diameter) was measured by 3 small size load cells $(1.2 \mathrm{~cm}$ in diamater, $0.4 \mathrm{~cm}$ in height, $5 \mathrm{~g}$ in weight and $5 \mathrm{~N}$ in capacity for each). The gauge showed linear characteristics for the load. A fringe $(4.5 \mathrm{~cm}$ in width and $0.6 \mathrm{~cm}$ in thickness) was provided outside of the pressure plate to eliminate the edge-effect of the gauge on the measurement. A micro-clinometer was set inside the fringe to monitor inclination of the gauge.

To minimize the disturbance of snow condition, a sophisticated procedure was applied for setting the gauge. A thin snow plate $(0.6 \mathrm{~cm}$ in thickness, $18 \mathrm{~cm}$ in width and $70 \mathrm{~cm}$ in length) was taken out from snow cover to be measured, making a thin cavity in the snow, by the use of a specially designed setting device. The gauge and the cord were placed in the snow plate fittingly as shown in Figure $4 \mathrm{~b}$, removing a part of the snow plate by the aid of a jig. Then the gauge was set in the thin cavity tightly by the setting device, together with the remaining original snow plate. The outputs of the gauge were recorded continously.

Two methods of stress determination from snow pressure are given separately (Oh'izumi and Huzioka 1985).

\section{CONCLUSION}

Four methods of measuring strain and pressure in snow are presented. The following were found. All work properly under normal conditions of snow. However, the hole-mark method does not allow a continuous measurement, and the short-span deformation gauge does not work for shearing deformation. Improvements of the two methods for these applications are necessary for the sophistication of research.

\section{REFERENCES}

Oh'izumi M, Huzioka T 1985 Determination of the principal stresses of a snow cover on a mountain slope using snow pressure gauges. Annals of Glaciology 6: 215-217

Shimizu H, Huzioka T 1975 Internal strains and stresses of snow cover on slopes. Snow Mechanics (Proceedings of the Grindelwald Symposium, April 1974): IAHS Publ. no 114: 321-331 